\title{
Raising a Child with Down Syndrome: Do Preferred Coping Strategies Explain Differences in Parental Health?
}

\author{
Tatjana Alexander ${ }^{1}$, Julia Walendzik ${ }^{2}$ \\ ${ }^{1}$ Department of Rehabilitation Psychology, Albrecht-Ludwigs-University of Freiburg, Freiburg, Germany \\ ${ }^{2}$ Department of Quantitative Methods, University of Technology, Berlin, Germany \\ Email: tatjanabarsk@gmx.de
}

Received 23 November 2015; accepted 9 January 2016; published 12 January 2016

Copyright (C) 2016 by authors and Scientific Research Publishing Inc.

This work is licensed under the Creative Commons Attribution International License (CC BY).

http://creativecommons.org/licenses/by/4.0/

\section{(c) (i) Open Access}

\begin{abstract}
The aim of this study was to determine coping strategies which may represent important personal resources and have a buffering effect in preventing mental health problems in parents of children with Down syndrome. Forty-nine parents of children with Down syndrome completed self-administrated measures of psychological and physical health problems, and coping behaviour, using several established measuring instruments. According to the hierarchical regression analyses, parents who often used regenerative coping strategies, and who experienced positive personal changes in terms of postraumatic growth suffered from less anxiety and somatisation symptoms, whereas dysfunctional coping was the best predictor for parental depression and physical symptoms. Regenerative coping mediated between parental tendency to recognize their emotional needs and somatisation symptoms. Intervention programs for families of children with Down syndrome may benefit if they address parents' reflection about their feelings, foster posttraumatic growth processes, and impart knowledge about long-term regenerative coping strategies.
\end{abstract}

\section{Keywords}

Down Syndrome, Intellectual Disability, Mental Health, Parents, Coping

\section{Introduction}

Raising a child with Down syndrome is a particular challenge for parents. The specific features of these children, constitutive for child-parent interaction patterns, were well described in empirical literature in the last years. The majority of them (95\%) have standard trisomy 21 . This is a genetic condition that continues to impact the individual development throughout childhood and into adulthood. Typical characteristics include serious learning 
difficulties, use of specific behavioural strategies to avoid learning opportunities (Wishart, 1993a; Wishart, 1993b; Feeley \& Jones, 2008; Næss et al., 2011; van Gameren-Oosterom et al., 2011; Daunhauer et al., 2014; Levy \& Eilam, 2013), attention deficits (Coe et al., 1999; Ekstein et al., 2011), and communication problems (Kumin, 2003; Visootsak et al., 2012). Further, in comparison to other children, children with Down syndrome show a great frequency of compulsive-like repetitive behaviours (for example, "repeating certain actions over and over" or "act out the same thing in pretend play", Evans \& Gray, 2000), higher rates of non-compliance, difficulties in dealing with hygiene, high rates of self-talk, and social withdrawal (Coe et al., 1999; Feeley \& Jones, 2008; Glenn \& Cunningham, 2000).

Besides deficits in cognitive and social areas, children with Down syndrome often have other comorbid chronic health conditions, such as congenital heart defects, gastrointestinal disease, hypothyroidism, respiratory disorders, ophthalmologic problems, and hearing problems (Freeman et al., 1998; Al-Aama et al., 2012; van Trotsenburg et al., 2006; Tüysüz \& Beker, 2001; Bloemers et al., 2007; Broers et al., 2012; Fimani et al., 2007; Stirn, 2012; Skott, 2006; Roizen et al., 2014), which make extra-care and extra-attention necessary and may be an additional source for parents' worries and fears. As a result, on the one hand, families of these children have to spend much energy and patience in managing the child's behavioural, emotional and health problems, and, on the other hand, parents of children with Down syndrome face different challenges arising from necessity of dealing with social consequences of the illness like potential threat of stigmatization. Intra-psychic, they may undergo a painful process in losing the imagination of having a "normal" child and to accepting that their child is "different".

Meaningful psychological, physical and social demands, arising out of the particular life situation of families with these children with very unique characteristics, may overstrain the families' capacities and resources, and result in increasing risk of parents' psychological problems, like depression, anxiety and somatisation symptoms (Scott et al., 1997; Spangenberg \& Theron, 2001; Spangenberg \& Theron, 2001; Gallagher et al., 2008; West, 1998; Gau, Chiu, \& Soong, 2008; Norizan \& Shamsuddin, 2010; Nes et al., 2014). However, several empirical investigations also documented examples of successful coping and positive psychological adjustment (Van Riper, 2007; King et al., 2006; King et al., 2012, Van Der Veek, Kraaij, \& Garnefski, 2009; Choi \& Yoo, 2015; Hsiao, 2014). Positive adaptation can occur in the form of changed world views concerning life and disability, gaining sense of coherence, and an appreciation of the positive contribution made by children to family members and society as a whole (King et al., 2006; Pillay, Girdler, Collins, \& Leonard, 2012; Choi, 2015). In view of these promising findings, showing ways for successful family' changes and corresponding adaptation, surprisingly little is known about how positive parental adjustment in terms of eligible change in priorities, openness and personal growth contribute to parents' psychological health. Are there individual differences in coping style, such as the ability to accept the new life situation as given instead of denial, and the willingness to grow from adversities, which make several parents resilient and keep their away from the development of psychopathological problems? This study was conceptualized in order to identify coping-related variables that account for dissimilarities in parental psychological and physical health.

The primary aim of the study was to determine general characteristics of parents' behaviour which may represent important personal resources and have a buffering effect in prevention of parents' psychological and physical health problems, in the interplay of stress factors arising from several difficulties of parent-child interaction and parental well-being and health. We hypothesized that parents who prevalently use adaptive coping strategies, such as emotional disclosure, finding opportunities to grow from the specific challenges of their life situation, and regenerative coping are at a low risk of psychological and physical health problems, compared to parents using rather dysfunctional strategies to cope with stressful factors in their lives.

Furthermore, we examined, to what extent the parental tendency to use dysfunctional or, by contrast, adaptive regenerative coping strategies, mediates the relationship between parents' readiness to reflect on their own feelings, i.e., parents' acknowledgment of their own emotional needs, and different indicators of parental mental as well as physical health.

\section{Methods}

\subsection{Design and Participants}

This cross-sectional study was approved by our local ethics committee. Parents were recruited via the Internet (a German Down syndrome electronic mailing list) and during two parents' meetings organized by the German 
Association for People with Intellectual Disabilities called "Lebenshilfe e.V.”. Informed consent was obtained from participants before enrolment. Parents who were interested in study participation were instructed to disclose their postal and email addresses.

The questionnaires were then mailed them. At the parents' meetings, some of the questionnaires were also distributed to the parents by the members of the project team on location. From the parents having received the questionnaires, $92 \%$ returned the completed questionnaires within four weeks.

In total, forty-nine parents returned the questionnaires, forty one mothers and eight fathers. The mean age was 40.24 years, varying from 27 to 52 years $(S D=6.75)$. Forty four $(90 \%)$ parents were married and lived together with the biological father/mother of their disabled child in charred housing. One person (2\%) lived together with a different partner, and four (8\%) were single parents. The mean educational level of the sample was high: twenty-one (43\%) had a university degree, nine (28\%) had a college degree, and seventeen (25\%) had a lower high school degree. Two parents (4\%) did not enter any educational level.

The mean age of the children with Down syndrome was 7.13 years and ranged between three months to seventeen years $(S D=5.34)$. On the average, 6.87 years had elapsed since the Down syndrome diagnosis. In twenty four (49\%) of the children, an additional chronicle disease or disorder was diagnosed. Most common was congenital heart disease (CHD, 13 children, 27\%). The rate of the congenital heart disease in this sample corresponded to a high prevalence of heart diseases in the population of young persons and children with Down syndrome (Vis et al., 2009; Narchi, 1999).

\subsection{Measuring Instruments}

\subsubsection{Health Indicators}

Somatisation, depression and anxiety subscales from the Brief Symptom Inventory (BSI, Derogatis, 1993) were used to assess parents' recent mental health status (all items scored 1-5). The somatisation subscale captures psychological distress resulting from the perception of body dysfunction (e.g., cardiovascular, gastrointestinal, and respiratory). The depression subscale addresses symptoms of clinical depressive syndrome, such as withdrawal of interest in life activities, dysphoric affect, and loss of energy. Typical anxiety symptoms measured with the anxiety subscale are nervousness, restlessness, and tension. Previous studies have revealed satisfactory internal reliability of above 0.70 and a good convergent validity for the separate BSI subscales (Derogatis \& Melisaratos, 1983; Derogatis, 1993).

To receive additional information concerning parents' somatic complaints, we applied the Freiburg Complaint List (the FBL-R, Batra, Slifkin, \& Fahrenberg, 1995). The FBL-R is a self-report standardized questionnaire that lists different general as well as specific physical complaints including fatigue, pain, sensory, cardiovascular, and gastrointestinal symptoms. Parents were asked how often they experience each of the different somatic complaints mentioned in the questionnaire (all items scored 1-5). The total score of the FBL-R was used in our study as an indicator of the self-reported physical well-being. Prior research provided empirical evidence for the concurrent validity of the Freiburg Complaint List. In a representative sample of adults, highly significant correlations were found between FBL-R scores and indicators of illness, health concern, and utilization of health services (Fahrenberg, 1995).

\subsubsection{Measures of Dysfunctional and Regenerative Coping}

Two psychometrically sound scales were applied to indicate the extent to which parents use adaptive as well as maladaptive coping strategies in stressful life situations. First, similarly to the procedure in other studies (Stanton et al., 2000a; Stanton et al., 2002), several items from COPE (Carver, Scheier, \& Weintraub, 1989), a well-established measure of coping processes, were combined to capture dysfunctional coping (Table 1). Participants were instructed to respond to items regarding "what do you usually do to cope with stressful situations in your life." Rated on 4-point item response format, sample items are "I say to myself that this isn't real" and "I blame myself for things that happened." The Cronbachs' alpha reliability of the whole dysfunctional coping scale in our sample was 0.73 . Second, in order to estimate the degree to which participants use regenerative coping that is not captured by the COPE, we composed a short scale consisting of 3 items (e.g., "I learn specific relaxation techniques”, Table 1). Its’ internal consistency was acceptable (Cronbachs’ alpha of 0.71 ).

\subsubsection{Emotional Processing}

The emotional processing scale of Stanton et al. (2000b) was used to measure how far the parents acknowledge 
Table 1. Composition of the dysfunctional and regenerative coping scales, items of the emotional processing scale.

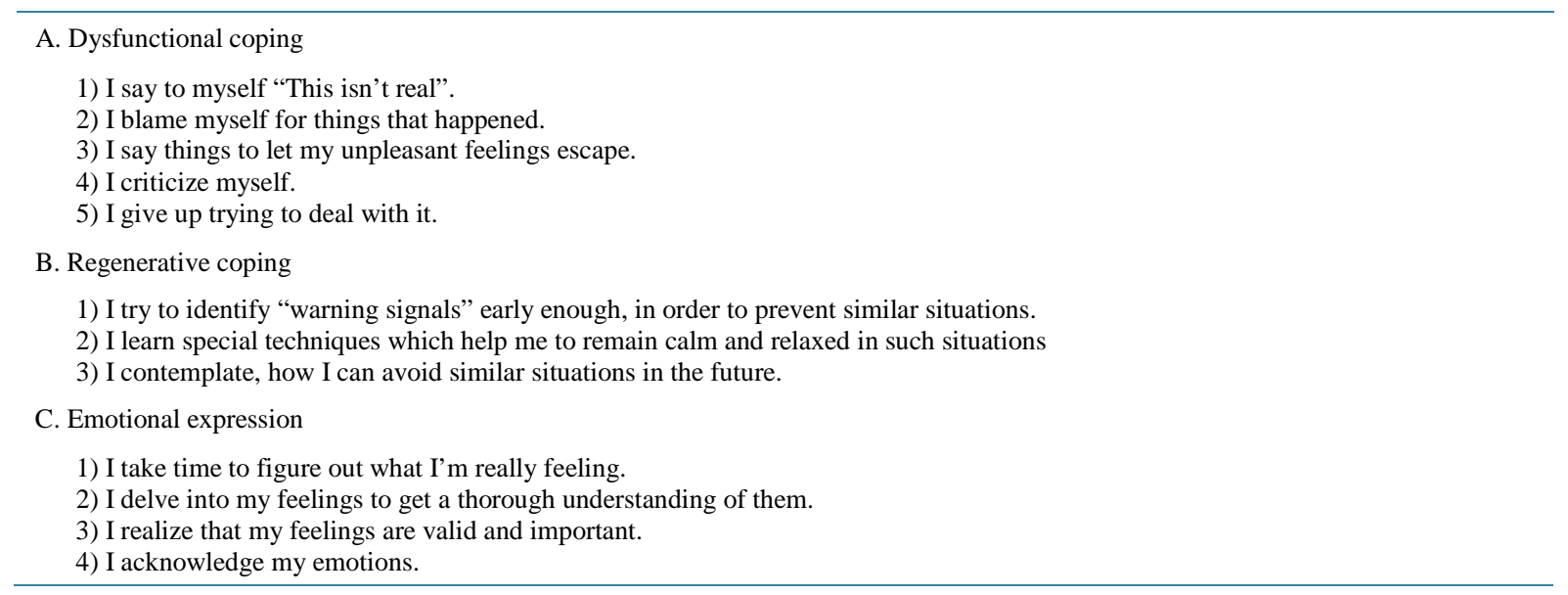

their emotions and try to understand the meaning of their feelings. The items are illustrated in Table 1 . Previous studies demonstrated high test-retest reliability, as well as convergent and discriminant validity of the emotional processing scale (Stanton et al., 2000b). Further, previous research supported the predictive validity of the emotional approach coping scales with regard to the adjustment to stressful encounters (Stanton et al., 2000b).

\subsubsection{Posttraumatic Growth}

Parents responded to the 36 items of the Posttraumatic Growth Status Inventory (PGSI, Alexander \& Oesterreich, 2013). Each item is rated using a 7-point Likert scale, ranging from 1 (does not apply) to 7 (completely applies). Items address the following seven posttraumatic growth domains: appreciation for life (e.g., "Every day is special to me”), relationships to others (e.g., "I know I can depend on others in difficult times”), new possibilities (e.g., I know from experience that difficult and fearful events can bring about various unexpected possibilities), personal strength (e.g., "I can handle difficulties well”), spirituality (e.g., "I have a pronounced religious or spiritual faith”), openness (e.g., "I enjoy listening to others opinions even when they contradict what my convictions are”), and generativity (e.g., "I enjoy sharing my experiences to help others to find a solution to their problems”). Unlike other contemporary available retrospective growth scales (e.g., Tedeschi \& Calhoun, 1996), the PGSI allows for estimating the actual profile of different growth-related aspects. Accordingly, when completing the inventory, respondents do not need to remember how they were prior to their crucial experience (in this particular case, the awareness of the child's diagnosis); they should simply describe their actual behaviour, thinking and feelings. Previous research demonstrated good convergent and construct validity as well as internal reliability (Cronbach’s Alpha of 0.93) of the PGSI (Alexander \& Oesterreich, 2013).

\subsection{Data Analyses}

First, we completed descriptive statistics to gain systematic information on the occurrence of mental and physical health complaints in the sample of 49 parents of children with Down syndrome. Second, several hierarchical regression analyses were performed in which parents' anxiety, depression, somatisation and physical complaints scores were regressed on variables representing parents' understanding and acknowledgement of their feelings, coping strategies as well as the current state in the processes of posttraumatic growth. The participants' sex and emotional processing score were entered into the equation in Step 1; the regenerative and dysfunctional coping were included in Step 2 and Step 3, respectively. The total score of the Posttraumatic Growth Status Inventory was entered in Step 4. We tested mediation effects of both regenerative and dysfunctional coping, with the method specified by Baron and Kenny (Baron \& Kenny, 1986; Frazier, Tix, \& Baron, 2004). In particular, we first tested all of the criteria for mediation. Sobel’s test statistic (MacKinnon, Warsi, \& Dwyer, 1995) was then used to assess the significance of mediation effects.

\section{Results}

The average parents' scores on BSI depression, anxiety and somatisation subscales were 0.29 (SD = 0.42$)$, 0.45 
$(\mathrm{SD}=0.43)$, and $0.30(\mathrm{SD}=0.42)$ for mothers; and $0.20(\mathrm{SD}=0.27), 0.25(\mathrm{SD}=0.21)$, and $0.03(\mathrm{SD}=0.49)$ for fathers, respectively. (According to the recommendations for users of the German BSI version (Franke, 2000), the average subscales' scores correspond to the quotient of the mean subscale sum value and the number of the subscale items.) Compared to the norm values from the German general population, mothers of children with Down syndrome showed higher levels of anxiety symptoms $(M=0.45$ in the sample vs. $M=0.39$ in the general population of adult women). Mothers' degrees of depression and somatisation symptoms were not higher than the corresponding norm values. Fathers' values on all three BSI subscales were somewhat lower than the norm values from German general population of male adults. On the somatisation scale, the difference to the norm values was substantial $(M=0.03$ in the sample vs. $M=0.23$ in the general population), indicating that fathers of children with Down syndrome from study sample reported fewer somatisation symptoms than adult men of the general population.

In an attempt to address whether the predictors had differential effects on four separate indicators of parents' mental and physical health (BSI anxiety, depression, and somatisation symptoms as well as physical complaints as captured with the FBL), several hierarchical regression analyses were performed (see Tables 2-5). Parents' somatic and psychological symptoms were regressed on predictor variables in the following order: parents' sex and emotional processing entered in Step 1, regenerative coping entered in Step 2, dysfunctional coping entered in Step 3, and parents' values on posttraumatic growth scale were added to the model at Step 4.

After accounting for the sex and emotional processing (Step 1 of the regression analysis), more anxiety and somatisation symptoms were predicted by less frequent usage of regenerative coping strategies and a lower level of changes corresponding with the processes of posttraumatic growth. Additionally, parental tendency to use dysfunctional coping strategies was a powerfully statistically significant predictor of anxiety symptoms $(\beta=0.55$;

Table 2. Regressions of parents' anxiety symptoms on five predictor variables ( $\mathrm{N}=49)$.

\begin{tabular}{|c|c|c|c|c|c|c|c|c|c|c|c|c|c|c|c|}
\hline & & Step1 & & & Step 2 & & & Step & & & Step & & & & \\
\hline Predictors & B & $S E B$ & $\beta$ & B & $S E B$ & $\beta$ & B & $S E B$ & $\beta$ & B & $S E B$ & $\beta$ & $\mathrm{R}^{2}$ total & $\begin{array}{c}\mathrm{R}^{2} \\
\text { adjusted }\end{array}$ & $\Delta \mathrm{R}^{2}$ \\
\hline Sex & 2.57 & 1.27 & $0.30^{*}$ & 1.66 & 1.34 & 0.19 & 0.95 & 1.15 & 0.11 & 0.92 & 1.12 & 0.11 & & & \\
\hline $\begin{array}{l}\text { Emotional } \\
\text { processing }\end{array}$ & -0.20 & 0.09 & $-0.34^{*}$ & -0.12 & 0.10 & -0.21 & -0.04 & 0.08 & -0.07 & 0.10 & 0.11 & 0.17 & $0.14^{*}$ & $0.10^{*}$ & \\
\hline $\begin{array}{l}\text { Regenerative } \\
\text { coping }\end{array}$ & & & & -0.44 & 0.25 & $-0.27^{*}$ & -0.70 & 0.22 & $-0.44^{* *}$ & -0.61 & 0.22 & $-0.39^{* *}$ & $0.19^{*}$ & $0.14^{*}$ & 0.05 \\
\hline $\begin{array}{l}\text { Dysfunctional } \\
\text { coping }\end{array}$ & & & & & & & 0.61 & 0.13 & $0.54^{* * *}$ & 0.62 & 0.13 & $0.55^{* *}$ & $0.46^{* * *}$ & $0.41^{* * *}$ & 0.27 \\
\hline $\begin{array}{l}\text { Posttraumatic } \\
\text { growth }\end{array}$ & & & & & & & & & & -0.04 & 0.02 & $-0.33^{*}$ & $0.50^{* * *}$ & $0.44^{* * *}$ & 0.04 \\
\hline
\end{tabular}

${ }^{*} p<0.05,{ }^{* *} p<0.01,{ }^{* * *} p<0.001$.

Table 3. Regressions of parents’ BSI somatisation symptoms on five predictor variables $(\mathrm{N}=49)$.

\begin{tabular}{|c|c|c|c|c|c|c|c|c|c|c|c|c|c|c|c|}
\hline & & Step1 & & & Step 2 & & & Step 3 & & & Step 4 & & & & \\
\hline Predictors & B & $S E B$ & $\beta$ & B & $S E B$ & $\beta$ & B & $S E B$ & $\beta$ & B & $S E B$ & $\beta$ & $\mathrm{R}^{2}$ total & $\begin{array}{c}\mathrm{R}^{2} \\
\text { adjusted }\end{array}$ & $\Delta \mathrm{R}^{2}$ \\
\hline Sex & 3.46 & 1.48 & $0.34^{*}$ & 2.02 & 1.52 & 0.20 & 1.69 & 1.52 & 0.17 & 1.64 & 1.45 & 0.17 & & & \\
\hline $\begin{array}{l}\text { Emotional } \\
\text { processing }\end{array}$ & -0.18 & 0.10 & $-0.26^{*}$ & -0.05 & 0.11 & -0.07 & -0.03 & 0.11 & -0.05 & 0.20 & 0.14 & 0.29 & $0.13^{*}$ & $0.09^{*}$ & \\
\hline $\begin{array}{l}\text { Regenerative } \\
\text { coping }\end{array}$ & & & & -0.44 & -0.69 & $-0.38^{* *}$ & -0.79 & 0.29 & $-0.44^{* *}$ & -0.65 & 0.28 & $-0.36^{*}$ & $0.23^{*}$ & $0.18^{*}$ & 0.10 \\
\hline $\begin{array}{l}\text { Dysfunctional } \\
\text { coping }\end{array}$ & & & & & & & 0.11 & 0.18 & 0.08 & 0.12 & 0.17 & 0.10 & $0.26^{*}$ & $0.19^{*}$ & 0.03 \\
\hline $\begin{array}{l}\text { Posttraumatic } \\
\text { growth }\end{array}$ & & & & & & & & & & -0.07 & 0.03 & $-0.47^{*}$ & $0.34^{* *}$ & $0.26^{* *}$ & 0.08 \\
\hline
\end{tabular}


Table 4. Regressions of parents' depression symptoms on five predictor variables $(\mathrm{N}=49)$.

\begin{tabular}{|c|c|c|c|c|c|c|c|c|c|c|c|c|c|c|c|}
\hline & & Step 1 & & & Step 2 & & & Step 3 & & & Step 2 & & & & \\
\hline Predictors & B & $S E B$ & $\beta$ & B & $S E B$ & $\beta$ & B & $S E B$ & $\beta$ & B & $S E B$ & $\beta$ & $\mathrm{R}^{2}$ total & $\begin{array}{c}\mathrm{R}^{2} \\
\text { adjusted }\end{array}$ & $\Delta \mathrm{R}^{2}$ \\
\hline Sex & 1.74 & 1.24 & 0.21 & 1.42 & 1.36 & 0.17 & 0.84 & 1.27 & 0.10 & 0.83 & 1.28 & 0.10 & & & \\
\hline $\begin{array}{l}\text { Emotional } \\
\text { processing }\end{array}$ & -0.21 & 0.08 & $-0.37^{* *}$ & -1.18 & 0.09 & $-0.32^{*}$ & -0.12 & 0.09 & -0.21 & -0.11 & 0.13 & -0.19 & $0.13^{*}$ & $0.09^{*}$ & \\
\hline $\begin{array}{l}\text { Regenerative } \\
\text { coping }\end{array}$ & & & & -0.15 & 0.25 & -0.10 & -0.37 & 0.24 & -0.24 & -0.36 & 0.25 & -0.23 & $0.13^{*}$ & 0.08 & 0.00 \\
\hline $\begin{array}{l}\text { Dysfunctional } \\
\text { coping }\end{array}$ & & & & & & & 0.46 & 0.14 & $0.42^{* *}$ & 0.46 & 0.15 & $0.42^{* *}$ & $0.30^{* *}$ & $0.23^{* *}$ & 0.17 \\
\hline $\begin{array}{l}\text { Posttraumatic } \\
\text { growth }\end{array}$ & & & & & & & & & & 0.00 & 0.26 & -0.03 & $0.30^{* *}$ & $0.21^{* *}$ & 0.00 \\
\hline
\end{tabular}

Table 5. Regressions of parents’ FBL somatic complaints on five predictor variables $(\mathrm{N}=49)$.

\begin{tabular}{|c|c|c|c|c|c|c|c|c|c|c|c|c|c|c|c|}
\hline & & Step1 & & & Step 2 & & & Step 3 & & & Step 4 & & & & \\
\hline Predictors & B & $S E B$ & $\beta$ & B & SE B & $\beta$ & B & $S E B$ & $\beta$ & B & $S E B$ & $\beta$ & $\begin{array}{c}\mathrm{R}^{2} \\
\text { total }\end{array}$ & $\begin{array}{c}\mathrm{R}^{2} \\
\text { adjusted }\end{array}$ & $\Delta \mathrm{R}^{2}$ \\
\hline Sex & 9.72 & 5.07 & $0.27^{*}$ & 7.90 & 5.51 & 0.22 & 5.44 & 5.24 & 0.16 & 5.35 & 5.21 & 0.15 & & & \\
\hline $\begin{array}{l}\text { Emotional } \\
\text { processing }\end{array}$ & -1.00 & 0.34 & $-0.42^{* *}$ & -0.84 & 0.39 & $-0.35^{*}$ & -0.67 & 0.38 & $-0.28^{*}$ & -0.22 & 0.52 & -0.10 & $0.17^{*}$ & $0.14^{*}$ & \\
\hline $\begin{array}{l}\text { Regenerative } \\
\text { coping }\end{array}$ & & & & -0.88 & 1.03 & -0.14 & -1.64 & 1.00 & -0.26 & -1.38 & 1.02 & -0.22 & $0.19^{*}$ & $0.13^{*}$ & 0.02 \\
\hline $\begin{array}{l}\text { Dysfunctional } \\
\text { coping }\end{array}$ & & & & & & & 1.38 & 0.61 & $0.31^{*}$ & 1.42 & 0.61 & $0.31^{*}$ & $0.29^{* *}$ & $0.23^{* *}$ & 0.10 \\
\hline $\begin{array}{l}\text { Posttraumatic } \\
\text { growth }\end{array}$ & & & & & & & & & & -0.13 & 0.11 & -0.26 & $0.32^{* *}$ & $0.24^{* *}$ & 0.03 \\
\hline
\end{tabular}

$p=0.00)$, but it was not related to parents' somatisation symptoms ( $\beta=0.10 ; p=0.47)$. Parents, who more frequently applied dysfunctional coping, reported significantly more pronounced anxiety symptoms.

The predictors explained 50\% of the variance in anxiety and 34\% of variance in somatisation symptoms in the complete model. Also, after each separate regression step, the total adjusted $\mathrm{R}^{2}$ was statistically significant different from zero (see Table 2 and Table 3). This revealed that the tested models (which contained two, three, four or five predictors, respectively) were well suited to explain parental levels of anxiety and somatisation symptoms. Thereby, the whole model including all five predictor variables proved to be a model with the strongest explanative power.

Table 4 demonstrates the results of the hierarchical regression analyses with the parents' depression as an outcome variable. Although emotional processing was highly significant associated with depression symptoms after the first and the second regression analyses steps, it did not reach the threshold value for statistical significance in the whole model. After including regenerative coping, dysfunctional coping as well as parental posttraumatic growth in the model, more depression-related symptoms were significantly associated with a higher rate of usage dysfunctional coping strategies. All predictors explained 30\% of the variance in depressive symptoms.

Additional hierarchical regression analyses were completed to investigate the impact of coping-related predictor variables on parents' somatic complaints (Table 5). Similar to the study results concerning parental depression symptoms, emotional processing was statistically significant, inversely associated with parents' somatic complaints after initial analysis steps, but not in the whole model. Further, dysfunctional coping showed the highest predictive value after entering the complete set of variables into the regression equation. Although the direction of the relationships from parental regenerative coping and posttraumatic growth to their somatic com- 
plaints were consistent with the assumptions (more use of regenerative coping and more pronounced posttraumatic growth related to a lower level of physical complaints), the corresponding beta-weights did not reach the criterion for statistical significance ( $\beta=-0.22, p>0.05$ and $\beta=-0.26, p>0.05$ ).

To summarise the findings of the regression analyses, three points are particularly noteworthy. First, regenerative coping and posttraumatic growth were statistically significant inversely associated with parents' anxiety and somatisation symptoms, but not with their levels of depression-related symptomatology and FBL somatic complaints. Second, dysfunctional coping showed the highest explanative power in prediction of parents' anxiety, depression, and somatisation symptoms. Third, parents' tendency to appreciate and to reflect their feelings (as represented through the emotional processing variable) was statistically significant negatively associated with all four indicators of parental health after initial analyses steps. However, this predictor lost its' explanative power in the whole model in context of all predictor variables, and was no longer significant.

\subsection{Does Parents' Inclination to Use Regenerative Coping Mediate the Relationship between Parental Openness towards Their Own Feelings and Their Psychological Health?}

Next, we evaluated the hypothesis that the parents' disposition to use regenerative coping strategies should mediate the relation between their readiness to appreciate their own feelings, as captured with the emotional processing scale, and parental mental health. According to Baron and Kenny (1986) and Frazier et al. (2004), mediation takes place, if the following requirements are fulfilled: a) the predictor must show a significant relationship to the proposed mediator and the criterion, $b$ ) the mediator must be related to the criterion, and c) the relationship between the predictor and the criterion must be reduced when the mediator is entered into the equation. If the relation between the predictor and the criterion, controlling for the mediator, is substantial reduced, but still greater than zero, the data suggest partial mediation.

In order to identify eligible mediating effects, we first examined the relationship between emotional processing and indicators of parents' psychological health and then between psychological health indicators and regenerative coping (Conditions a and b). Parents' values on emotional processing scale were entered into the equation in Step 1. Parents' use of regenerative coping was included in Step 2. The results of these analyses showed significant associations of parents' emotional processing to all three mental health indicators (anxiety, depression, and somatisation symptoms, respectively). Further, the regenerative coping was significantly related to parents' anxiety and somatisation $(\beta=-0.27 ; p<0.05$ and $\beta=-0.38 ; p<0.01)$, indicating that the second mediation requirement was fulfilled for two measures of mental health: anxiety as well as somatisation symptoms.

We continued the analysis of mediating effects by assessing, whether the third mediation requirement was met in the case of parental level of anxiety symptomatology as a criterion variable. The results of these analyses showed a significant association of emotional processing to anxiety $(\beta=-0.34 ; p<0.05)$, which was reduced after the inclusion of parents' disposition to use regenerative coping into the model $(\beta=-0.21 ; p>0.05)$. The Sobel test statistic (MacKinnon et al., 1995; see Figure 1) offered, that the relation between emotional processing and anxiety was significantly attenuated when regenerative coping was included in the equation $(p=0.034)$, indicating that the frequency to which parents cope with stressful life situations by using regenerative coping mediated the relation between emotional processing and anxiety symptoms. Using procedures described by Shrout \& Bolger (2002), we calculated that $26 \%$ of the total relation between emotional processing and anxiety symptoms was mediated by parents' regenerative coping behaviour.

Next, we evaluated, whether the same mediating effect of regenerative coping plays a role in predicting parental somatisation symptoms. Satisfying the first requirement, emotional processing was significantly related to the regenerative coping and to somatisation symptoms (see Figure 1 and Table 3). Satisfying the second requirement, the regenerative coping was related to somatisation symptoms, controlling for emotional processing in a multiple regression $(\beta=-0.44, p<0.01)$. The third requirement was that the relation between emotional processing and somatisation should be significantly smaller when the regenerative coping is entered as a predictor. Supporting this requirement, the relation between emotional processing and somatisation was substantially reduced when regenerative coping behaviour was included in the regression model $(\beta=-0.07 ; p>0.05)$. Sobel's test was significant, indicating that the relation between emotional processing and somatisation decreased significantly when regenerative coping was included in the equation $(p=0.018)$. Finally, following guidelines provided by Shrout \& Bolger (2002), we calculated that $58 \%$ of the total effect of emotional processing on 

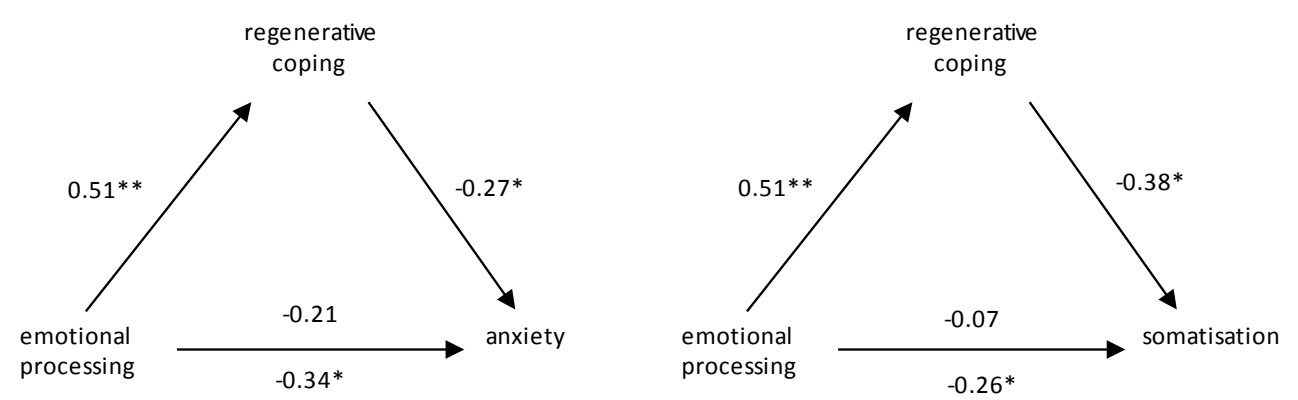

Note. The coefficients represent standardized beta weights. The coefficient below the horizontal arrow co rrespondents to the beta weight after controlling for the mediator variable

Figure 1. Mediating effect of regenerative coping in the relationships between parental emotional processing and anxiety as well as somatisation symptoms.

somatisation was mediated by regenerative coping.

To outline the results reported in this chapter, the analyses provided empirical evidence for mediating effects of regenerative coping in the relationship between emotional processing and parents' anxiety as well as somatisation symptoms. However, the mediating role of regenerative coping was confined to these outcome measures. Parents' depression symptomatology was not statistically significant associated with regenerative coping behaviour.

\subsection{Does Parental Dysfunctional Coping Behaviour Mediate the Effect of Emotional Processing on Health Indicators?}

To address this question, we first established whether the mediations' conditions were met for parental tendency to use dysfunctional coping strategies. Satisfying the first requirement, emotional processing was significantly related to indicators of parental health (Tables 2-5). However, the association between parents' disposition to reflect and to acknowledge their feelings (as captured with emotional processing variable) and parents' dysfunctional coping behaviour $(p=0.56$ ) was not significant. Consequently, the entire requirements for mediation were not fulfilled.

\section{Discussion}

The aim of this study was to investigate, whether the using of regenerative and dysfunctional coping strategies as well as emotional openness and posttraumatic growth may explain the health-status related differences in parents of children with Down syndrome. In attempt to highlight complex impact chains in relationships between parents' coping behaviour and, on the other hand, various indicators of their mental and physical health, we conducted multivariate regression analyses allowing for the testing of potential mediating effects. Parents' adjustment to their specific life situation may depend on their willingness and ability to release the inner image of "normal child', including the dealing with the feelings of loss, and to accept the child as it is. The success of the adaptation process may depend on parents' ability and willingness to face up to their true feelings and to acknowledge also negative emotions and perceptions. As a consequence, they could attain a deep understanding of their selves and become more flexible in deliberating between suitable strategies to cope with challenges resulting from several potential sources of strain, such as the special features of the child's behaviour, and the need to pay extra attention to child's comorbid physical health problems. Those parents may also better manage occasional social consequences such as a risk of stigmatisation, the fear of being treated in a different way, and worries about future child's social integration. Referring to this, we hypothesised that parents who are open and reflective of their own intra-psychic processes, including their feelings and emotions, would be inclined to use adaptive regenerative coping strategies instead of dysfunctional stress-related behaviour like self-blaming and denial. This in turn would then have a positive impact on their psychological and physical health.

In keeping with previous findings from research on parents of children with different kinds of developmental disorders (Baker et al., 2005; Dunn et al., 2001, van Der Veek, Kraaij, \& Garnefski, 2009; Zablotsky, Bradshaw, \& Stuart, 2012; Oelofsen \& Richardson, 2006; Norizan \& Shamsuddin, 2010, Hall et al., 2012; Thabet et al., 
2013), the results of presented study highlighted a potential value of individual coping style for the psychological health of parents of children with Down syndrome. Moreover, significant relationships of parental coping strategies to their physical well-being were demonstrated. This last finding seems to be particularly important, as there are yet only few studies investigating the relationships between parents' physical health and coping related variables. Thus, Song et al. (2014) showed, that parents who were able to feel more positive affects (like to be optimistic or proud of one self) had better values on a cumulative physiological index, known as allostatic load. Another study (Cantwell, Muldoon, \& Gallagher, 2015) demonstrated a positive relationship between self-reported parental mastery und physical health.

Interestingly, regression analyses offered systematic differences in pattern of correlations between coping related variables and separate indicators of parents' mental and physical health. Regenerative coping, posttraumatic growth, and emotional processing showed the strongest explanatory power in the prediction of anxiety and somatisation symptoms, whereas dysfunctional coping was the best predictor for parental depression and physical complaints. Furthermore, regenerative coping exerted a mediating effect in the prediction of parents' anxiety as well as somatisation symptoms, but not in the prediction of depression and somatic complaints. In contrast to adaptive regenerative coping, dysfunctional coping failed to mediate between parents' emotional processing and indicators of parental health.

In other words, parents who often used regenerative coping strategies, who experienced positive personal changes in terms of posttraumatic growth, and who reflected on their own feelings and emotions instead of denial, suffered from less anxiety and somatisation symptoms. Additionally, parents who paid more attention to their feelings and acknowledged their own psychological needs used more frequently adaptive regenerative coping, such as learning of special relaxation techniques and considering general strategies to circumvent similar stress-induced factors. However, the degree to which parents reflected about their feelings was not related to the dysfunctional coping behaviour. Parents who showed more acknowledgements for their own psychological needs did not less often use dysfunctional coping, comparing to parents with a lower tendency of recognizing for their own emotional needs and feelings. These findings may point to a principally different nature of psychological mechanisms underlying parents' tendency to use adaptive and, by contrast, dysfunctional coping strategies. Moreover, adaptive and dysfunctional coping seems to be non-complementary in relation to each other.

Several limitations should be kept in consideration regarding the findings reported above. In an attempt to point out multicomponent functional chains contributing to parental resistance towards mood disorders and their resilience in physical health, we conducted complex statistical analyses including tests for mediating effects. However, due to a cross-sectional study design, unambiguous inferences regarding the directionality of relational dynamics cannot be made. Although it seems more plausible to conclude that parents, who pay extra attention to their emotional needs and reflect on the causes for their feelings, more likely favour adaptive regenerative coping, and this in turn has a positive effect on their psychological health, an alternative model of opposite relationships would also be partial consistent with the correlation pattern in empirical data. Thus, it could be a case that parents who suffered from more anxiety and somatisation symptoms are limited in their psychological capacity to contemplate and to use long-term behavioural strategies like learning relaxation techniques and that those parents tend to avoid reflection about their feelings due to fear of increased emotional distress. Further, parents with pronounced anxiety symptoms may perceive many potentially neutral stimuli, e.g. particular features of child's behaviour, such as child's self-talking, as worrying. This general reaction tendency may limit their opportunities for intra-psychical growth. Additional longitudinal studies are necessary to clarify the direction of possible causal relationships between variables representing parental coping style and indicators of their mental and physical health. Since our sample consisted predominantly on mothers raising children with Down syndrome, additional research is also warranted to investigate, whether fathers and mothers use different coping strategies, and to reveal possible dissimilarities in the impact of individual coping behaviour on mothers' and fathers' health. More research work is also needed to investigate, whether various kinds of parental coping behaviour have unequal adaptive significance during different periods of time after child’s birth.

\section{Conclusion}

Knowledge about potentially salutary effects of several adaptive coping strategies on parent' health could be considered during the development and implementation of intervention programs designed to support families of 
children with Down syndrome and to enhance parental well-being and quality of life. Interventions may benefit if they address parents' reflection about their emotional needs and intra-psychic processes, inspire re-evaluating values and priorities of life, and impart knowledge about long-term regenerative coping strategies.

\section{References}

Al-Aama, J. Y., Bondagji, N. S., \& El-Harouni, A. A. (2012). Congenital Heart Defects in Down Syndrome Patients from Western Saudi Arabia. Saudi Medical Journal, 33, 1211-1215.

Alexander, T., \& Oesterreich, R. (2013). Development and Evaluation of the Posttraumatic Growth Status Inventory. Psychology, 4, 831-844. http://dx.doi.org/10.4236/psych.2013.411120

Baker, B. L., Blacher, J., \& Olsson, M. B. (2005). Preschool Children with and without Developmental Delay. Behavior Problems, Parents’ Optimism and Well-Being. Journal of Intellectual Disability Research, 49, 575-590. http://dx.doi.org/10.1111/j.1365-2788.2005.00691.x

Baron, R. M., \& Kenny, D. A. (1986). The Moderator-Mediator Variable Distinction in Social Psychological Research: Conceptual, Strategic, and Statistical Considerations. Journal of Personality and Social Psychology, 51, 1173-1182. http://dx.doi.org/10.1037/0022-3514.51.6.1173

Bloemers, B. L., van Furth, A. M., Weijerman, M. E., Gemke, R. J., Broers, C. J., van den Ende, K., Kimpen, J. L., Strengers, J. L., \& Bont, L. J. (2007). Down Syndrome: A Novel Risk Factor for Respiratory Syncytial Virus Bronchiolitis-A Prospective Birth-Cohort Study. Pediatrics, 120, 1076-1081. http://dx.doi.org/10.1542/peds.2007-0788

Broers, C. J., Gemke, R. J., Weijerman, M. E., Kuik, D. J., van Hoogstraten, I. M., \& van Furth, A. M. (2012). Frequency of Lower Respiratory Tract Infections in Relation to Adaptive Immunity in Children with Down Syndrome Compared to Their Healthy Siblings. Acta Paediatrica, 101, 862-867. http://dx.doi.org/10.1111/j.1651-2227.2012.02696.x

Cantwell, J., Muldoon, O., \& Gallagher, S. (2015). The Influence of Self-Esteem and Social Support on the Relationship between Stigma and Depressive Symptomology in Parents Caring for Children with Intellectual Disabilities. Journal of Intellectual Disability Research, 59, 948-957. http://dx.doi.org/10.1111/jir.12205

Carver, C. S., Scheier, M. F., \& Weintraub, J. K. (1989). Assessing Coping Strategies: A Theoretically Based Approach. Journal of Personality and Social Psychology, 56, 267-283. http://dx.doi.org/10.1037/0022-3514.56.2.267

Choi, E. K., \& Yoo, I. Y. (2015). Resilience in Families of Children with Down Syndrome in Korea. International Journal of Nursing Practice, 21, 532-541. http://dx.doi.org/10.1111/ijn.12321

Choi, H. (2015). Adaption in Families of Children with Down Syndrome: A Mixed-Methods Design. Journal of Korean Academy of Nursing, 45, 501-512. http://dx.doi.org/10.4040/jkan.2015.45.4.501

Coe, D. A., Matson, J. L., Russell, D. W., Slifer, K. J., Capone, G. T., Baglio, C., \& Stallings, S. (1999). Behavior Problems of Children with Down Syndrome and Life Events. Journal of Autism and Developmental Disorders, 39, 149-156. http://dx.doi.org/10.1023/A:1023044711293

Daunhauer, L. A., Fidler, D. J., Hahn, L., Will, E., Lee, N. R., \& Hepburn, S. (2014). Profiles of Everyday Executive Functioning in Young Children with Down Syndrome. American Journal of Intellectual and Developmental Disabilities, 119, 303-318. http://dx.doi.org/10.1352/1944-7558-119.4.303

Dunn, M. E., Burbine, T., Bowers, C. A., \& Tantleff-Dunn, S. (2001). Moderators of Stress in Parents of Children with Autism. Community Mental Health Journal, 37, 39-52. http://dx.doi.org/10.1023/A:1026592305436

Ekstein, S., Glick, B, Weill, M., Kay, B., \& Berger, I. (2011). Down Syndrome and Attention-Deficit/Hyperactivity Disorder (ADHD). Journal of Child Neurology, 26, 1290-1295. http://dx.doi.org/10.1177/0883073811405201

Evans, D. W., \& Gray, F. L. (2000). Compulsive-Like Behavior in Individuals with Down Syndrome: Its Relation to Mental Age Level, Adaptive and Maladaptive Behavior. Child Development, 71, 288-300. http://dx.doi.org/10.1111/1467-8624.00144

Feeley, K. M., \& Jones, E. A. (2008). Strategies to Address Challenging Behaviour in Young Children with Down Syndrome. Down Syndrome Research and Practice, 12, 153-163. http://dx.doi.org/10.3104/case-studies.2008

Fimani, F., Iovine, A., Carelli, R., Pansini, M., Sebastio, G., \& Magli, A. (2007). Incidence of Ocular Pathologies in Italian Children with Down Syndrome. European Journal of Ophthalmology, 17, 817-822.

Franke, H. F. (2000). Brief Symptom Inventory von L. R. Derogatis. Deutsche Version [Brief Symptom Inventory of L. R. Derogatis. German Version]. Göttingen: Beltz Test GmbH.

Frazier, P. A., Tix, A. P., \& Baron, K. E. (2004). Testing Moderator and Mediator Effects in Counseling Psychology Research. Journal of Counseling Psychology, 51, 115-134. http://dx.doi.org/10.1037/0022-0167.51.1.115

Freeman, S. B., Taft, L. F., Dooley, K. J., Allran, K., Sherman, S. L., Hassold, T. J., Khoury, M. J., \& Saker, D. M. (1998). Population-Based Study of Congenital Heart Defects in Down Syndrome. American Journal of Medical Genetics, 80, 213-217. http://dx.doi.org/10.1002/(SICI)1096-8628(19981116)80:3<213::AID-AJMG6>3.0.CO;2-8 
Gallagher, S., Phillips, A. C., Oliver, C., \& Carroll, D. (2008). Predictors of Psychological Morbidity in Parents of Children with Intellectual Disabilities. Journal of Pediatric Psychology, 33, 1129-1136. http://dx.doi.org/10.1093/jpepsy/jsn040

Gau, S. S. F., Chiu, Y. N., Soong, W. T., \& Lee, M. B. (2008). Parental Characteristics, Parenting Style, and Behavioural Problems among Chinese Children with Down Syndrome, Their Siblings and Controls in Taiwan. Journal of the Formosan Medical Association, 107, 693-703. http://dx.doi.org/10.1016/S0929-6646(08)60114-X

Glenn, S. M., \& Cunningham, C. C. (2000). Parents’ Reports of Young People with Down Syndrome Talking Loud to Themselves. Mental Retardation, 38, 498-505. http://dx.doi.org/10.1352/0047-6765(2000)038<0498:PROYPW>2.0.CO;2

Hall, H. R., Neely-Barnes, S. I., Graff, J. C., Krcek, T. E., Roberts, R. J., \& Hankins, J. S. (2012). Parental Stress in Families of Children with a Genetic Disorder/Disability and the Resiliency Model of Family Stress, Adjustment, and Adaptation. Issues in Comprehensive Pediatric Nursing, 35, 24-44. http://dx.doi.org/10.3109/01460862.2012.646479

Hsiao, C. Y. (2014). Family Demands, Social Support and Family Functioning in Taiwanese Families Rearing Children with Down Syndrome. Journal of Intellectual Disability Research, 58, 549-559. http://dx.doi.org/10.1111/jir.12052

King, G. A., Zwaigenbaum, L., King, S., Baxter, D., Rosenbaum, P., \& Bates, A. (2006). A Qualitative Investigation of Changes in the Belief Systems of Families of Children with Autism or Down Syndrome. Child: Care, Health \& Development, 32, 353-369. http://dx.doi.org/10.1111/j.1365-2214.2006.00571.x

King, G., Zwaigenbaum, L., Bates, A., Baxter, D., \& Rosenbaum, P. (2012). Parent Views of the Positive Contributions of Elementary and High School-Aged Children with Autism Spectrum Disorders and Down Syndrome. Child: Care, Health \& Development, 38, 817-828. http://dx.doi.org/10.1111/j.1365-2214.2011.01312.x

Kumin, L. (2003). Early Communication Skills for Children with Down Syndrome: A Guide for Parents and Professionals. Bethesda, MD: Woodbine House.

Levy, Y., \& Eilam, A. (2013). Pathways to Language: A Naturalistic Study of Children with Williams Syndrome and Children with Down Syndrome. Journal of Child Language, 40, 106-138. http://dx.doi.org/10.1017/S0305000912000475

MacKinnon, D. P., Warsi, G., \& Dwyer, J. H. (1995). A Simulation Study of Mediated Effect Measures. Multivariate Behavioral Research, 30, 41-62. http://dx.doi.org/10.1207/s15327906mbr3001_3

Næss, K. A., Lyster, S. A., Hulme, C., \& Melby-Lervåg, M. (2011). Language and Verbal Short-Term Memory Skills in Children with Down Syndrome: A Meta-Analytic Review. Research in Developmental Disabilities, 32, 2225-2234. http://dx.doi.org/10.1016/j.ridd.2011.05.014

Narchi, H. (1999). Neonatal ECG Screening for Congenital Heart Disease in Down Syndrome. Annals of Tropical Paediatrics: International Child Health, 19, 51-54. http://dx.doi.org/10.1037/a0035996

Nes, R. B., Roysamb, E., Hauge, L. J., Kornstadt, T., Landolt, M. A., Irgens, L. M., Eskedal, L., Kristensen, P., \& Vollrath, M. E. (2014). Adaption to the Birth of a Child with a Congenital Anomaly: A Prospective Longitudinal Study of Maternal Well-Being and Psychological Distress. Developmental Psychology, 50, 1827-1839. http://dx.doi.org/10.1037/a0035996

Norizan, A., \& Shamsuddin, K. (2010). Predictors of Parenting Stress among Malaysian Mothers of Children with Down Syndrome. Journal of Intellectual Disability Research, 54, 992-1003. http://dx.doi.org/10.1111/j.1365-2788.2010.01324.x

Oelofsen, N., \& Richardson, P. (2006). Sense of Coherence and Parenting Stress in Mothers and Fathers of Preschool Children with Developmental Disability. Journal of Intellectual and Developmental Disability, 31, 1-12. http://dx.doi.org/10.1080/13668250500349367

Pillay, D., Girdler, S., Collins, M., \& Leonard, H. (2012). “It’s Not What You Were Expecting, but It's Still a Beautiful Journey”: The Experience of Mothers of Children with Down Syndrome. Disability and Rehabilitation, 34, 1501-1510. http://dx.doi.org/10.3109/09638288.2011.650313

Roizen, N. J., Magyar, C. I., Kuschner, E. S., Sulkes, S. B., Druschel, C., van Wijngaarden, E., Rodgers, L., Diehl, A., Lowry, R. \& Hyman, S. L. (2014). A Community Cross-Sectional Survey of Medical Problems in 440 Children with Down Syndrome in New York State. Journal of Pediatrics, 164, 871-875. http://dx.doi.org/10.1016/j.jpeds.2013.11.032

Scott, B. S. S., Atkinson, L., Menton, H. L., \& Bowman, T. (1997). Psychological Distress of Parents of Infants with Down Syndrome. American Journal on Mental Retardation, 102, 161-171. http://dx.doi.org/10.1352/0895-8017(1997)102<0161:PDOPOI>2.0.CO;2

Shrout, P. E., \& Bolger, N. (2002). Mediation in Experimental and Non-Experimental Studies: New Procedures and Recommendations. Psychological Methods, 7, 422-445. http://dx.doi.org/10.1037/1082-989X.7.4.422

Skott, S. R. (2006). Down Syndrome: Common Otolaryngologic Manifestations. American Journal of Medical Genetics, Part C, Seminars in Medical Genetics, 142C, 131-140. http://dx.doi.org/10.1002/ajmg.c.30095

Song, J., Mailick, M. R., Ryff, C. D., Coe, C. L., Greenberg, J. S., \& Hong, J. (2014). Allostatic Load in Parents of Children with Developmental Disorders: Moderating Influence of Positive Affect. Journal of Health Psychology, 19, $262-272$. http://dx.doi.org/10.1177/1359105312468193

Spangenberg, J. J., \& Theron, J. C. (2001). Stress and Coping in Parents of Children with Down Syndrome. Studia Psychologica, 43, 41-48. 
Stanton, A. L., Danoff-Burg, S., Cameron, C. L., Bishop, M., Collins, C. A., Kirk, S., Sworowski, L. A., \& Twillman, R. (2000a). Emotionally Expressive Coping Predicts Psychological and Physical Adjustment to Breast Cancer. Journal of Consulting and Clinical Psychology, 68, 875-882. http://dx.doi.org/10.1037/0022-006X.68.5.875

Stanton, A. L., Danoff-Burg, S., Sworowski, L. A., Collins, C. A., Branstetter, A. D., Rodriguez-Hanley, A., Kirk, S. B., \& Austenfeld, J. L. (2002). Randomized, Controlled Trial of Written Emotional Expression and Benefit Finding in Breast Cancer Patients. Journal of Clinical Oncology, 20, 4160-4168. http://dx.doi.org/10.1200/JCO.2002.08.521

Stanton, A. L., Kirk, S. B., Cameron, C. L., \& Danoff-Burg, S. (2000b). Coping through Emotional Approach: Scale Construction and Validation. Journal of Personality and Social Psychology, 78, 1150-1169.

http://dx.doi.org/10.1037/0022-3514.78.6.1150

Stirn, K. B. (2012). Ocular Abnormalities and Systemic Disease in Down Syndrome. Strabismus, 20, 74-77. http://dx.doi.org/10.3109/09273972.2012.680234

Tedeschi, R. G., \& Calhoun, L. G. (1996). The Posttraumatic Growth Inventory: Measuring the Positive Legacy of Trauma. Journal of Traumatic Stress, 9, 455-471. http://dx.doi.org/10.1002/jts.2490090305

Thabet, B. J., Sallemi, R., Hasiri, I., Zouari, L., Kamoun, F., Zouari, N., Triki, C., \& Maalej, M. (2013). Psycho-Emotional Impact of a Child's Disability on Parents. Archives de Pédiatrie, 20, 9-16. (In French) http://dx.doi.org/10.1016/j.arcped.2012.10.024

Tüysüz, B., \& Beker, D. B. (2001). Thyroid Dysfunction in Children with Down’s Syndrome. Acta Paediatrica, 90, 13891393. http://dx.doi.org/10.1111/j.1651-2227.2001.tb01601.x

Van Der Veek, S. M. C., Kraaij, V., \& Garnefski, N. (2009). Down or Up? Explaining Positive and Negative Emotions in Parents of Children with Down's Syndrome: Goals, Cognitive Coping, and Resources. Journal of Intellectual and Developmental Disability, 34, 216-229. http://dx.doi.org/10.1080/13668250903093133

van Gameren-Oosterom, H. B., Fekkes, M., Buitendijk, S. E., Mohangoo, A. D., Bruil, J., \& Van Wouwe, J. P. (2011). Development, Problem Behavior, and Quality of Life in a Population Based Sample of Eight-Year-Old Children with Down Syndrome. PLoS ONE, 6, e21879. http://dx.doi.org/10.1371/journal.pone.0021879

Van Riper, M. (2007). Families of Children with Down Syndrome: Responding to “A Change in Plans” with Resilience. Journal of Pediatric Nursing, 22, 116-128. http://dx.doi.org/10.1016/j.pedn.2006.07.004

Van Trotsenburg, P. A. S., Heymans, H. S. A., Tijssen, J. G. P., de Vijlder, J. J. M., \& Vulsma, T. (2006). Comorbidity, Hospitalization, and Medication Use and Their Influence on Mental and Motor Development of Young Infants with Down Syndrome. Pediatrics, 118, 1633-1639. http://dx.doi.org/10.1542/peds.2006-1136

Vis, J. C., Duffels, M. G., Winter, M. M., Weijerman, M. E., Cobben, J. M., Huisman, S. A., \& Mulder, B. J. (2009). Down Syndrome: A Cardiovascular Perspective. Journal of Intellectual Disability Research, 53, 419-425. http://dx.doi.org/10.1111/j.1365-2788.2009.01158.x

Visootsak, J., Hess, B., Bakeman, R., \& Adamson, L. B. (2013). Effect of Congenital Heart Defects on Language Development in Toddlers with Down Syndrome. Journal of Intellectual Disability Research, 57, 887-892. http://dx.doi.org/10.1111/j.1365-2788.2012.01619.x

West, A. (1998). The Piloting of a Group for the Fathers of Children with Down Syndrome. Child: Care, Health and Development, 24, 289-294. http://dx.doi.org/10.1111/j.1365-2214.1998.tb00948.x

Wishart, J. (1993a). Learning the Hard Way: Avoidance Strategies in Young Children with Down’s Syndrome. Down Syndrome Research and Practice, 1, 47-55. http://dx.doi.org/10.3104/reviews.10

Wishart, J. (1993b). The Development of Learning Difficulties in Children with Down's Syndrome. Journal of Intellectual Disability Research, 37, 389-403. http://dx.doi.org/10.1111/j.1365-2788.1993.tb00882.x

Zablotsky, B., Bradshaw, C. P., \& Stuart, E. A. (2013). The Association between Mental Health, Stress, and Coping Supports in Mothers of Children with Autism Spectrum Disorders. The Journal of Autism and Developmental Disorders, 43, 1380-1393. http://dx.doi.org/10.1007/s10803-012-1693-7 